\title{
Science helps to rebuild Vietnam
}

\author{
Vietnam believes science to be the key to economic recovery. She hopes to have a \\ "modern scientific capability" within 15 years. Alastair Hay reports
}

$\mathrm{O}^{\mathrm{N}}$ NE of the longest wars in this century, the war in Vietnam, finally came to an end on 30 April 1975. It had claimed over a million lives and was fought for the best part of thirty years.

Few countries can have featured in as many television documentaries as Vietnam. For many of those watching, the image of Vietnam was fashioned by the television screen; it left a memory of a battered people and scarred countryside.

This is the legacy of war. Vietnam faces innumerable problems as she begins her programme of reconstruction. The problems in the health field illustrate the extent of the damage. The World Health Organisation cites figures from Vietnam of one million people infected by venereal disease, about 300,000 prostitutes, and half a million drug addicts, in a population of some 50 million. Endemic malaria affects some 18 million people in Vietnam. And the annual tuberculosis mortality rate is 30 per hundred thousand-the highest in the western Pacific.

Agricultural problems are just as daunting. Vietnam feeds 50 million people, but only farms 5 million hectares. Comparable figures for Eastern Europe cited by Vietnamese agriculturalists are estimated at a ratio of one person per hectare. If Vietnam is to become self-sufficient in food production-which is her intention-her tillage has to increase, and the efficiency of crop cultivation must improve.

But two obstacles impede her progress; unexploded weapons and bad weather. Literally hundreds of square miles of agricultural land have to lie fallow because of the presence of unexploded bombs and mines; minesweeping-currently being undertaken by the army-is required before the land can be pronounced safe.

The weather, too, has had disastrous consequences for the last two rice harvests. First it was too dry and then too cold. Yields have been too low to meet home demand and monthly rice rations have had to be reduced from 18 to 14 kilograms per person per month. To make up the remainder of the shortfall, scarce foreign currency had to be used to purchase rice on the international market. That currency was to have bought 3,000 tractors to aid the mechanisation of agriculture. In the event only 500 could be

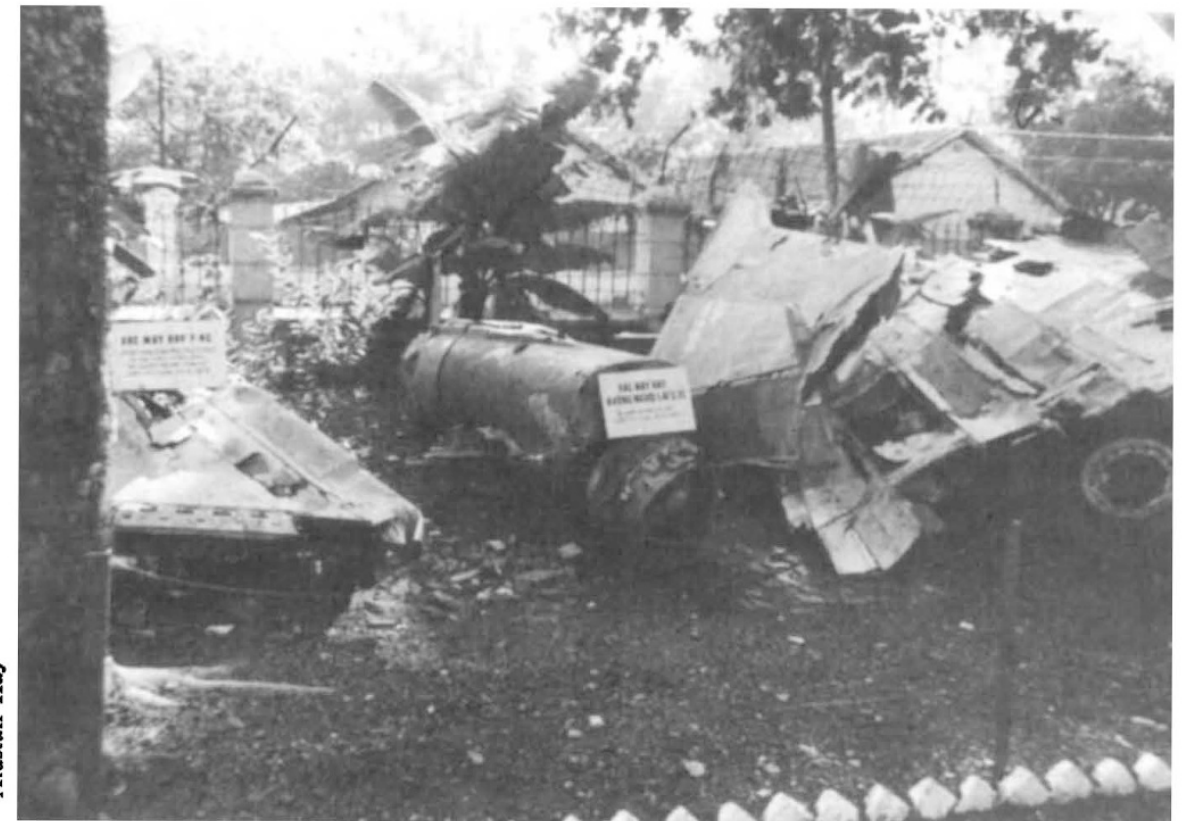

Suffering from the ravages of war

acquired, all of which are in use in the Mekong Delta-the country's most fertile region. 500 tractors for a population of 50 million people can hardly be expected to revolutionise Vietnamese agriculture.

It is against this background that the scientists in Vietnam are having to orientate their work. They may lack the necessary material resources to tackle many of the problems confronting the country, but they have no lack of prestige. Science is seen by the Government as the key to Vietnam's economic recovery. Science and technology are important enough to warrant a spokesman in the Politburo - the highest policy making body. The minister with this responsibility is General Vo Nguyen Giap.

Giap is not well known in the scientific world. As his title might suggest, his has been a military career. Giap's claim to fame is as victor of Dien Bien Phu, the battle which in 1954 signalled an end to French involvement in Indochina. He has had a number of other responsibilities before assuming the portfolio of Minister of Defence, a post he still retains.

Vietnam's scientists were not displeased when Giap was nominated to deal with their problems. They find him an able minister and effective spokesman. To have one of the seven members of the Politburo-and a possible future prime minister-as their representative is a situation any lobby would welcome.

Much of Vietnam's basic research is done in the Vietnamese Scientific Research Centre (VSRC) in Hanoi. The centre, now nearing completion, is part of the Soviet Union's aid programme to Vietnam. It will eventually house over 1,000 scientists, technologists and technicians in its four component institutes: those of biology, chemistry, physics and earth sciences. Two additional institutes (of oceanography and experimental biology) are located in the south of the country in Ho Chi Minh City (formerly Saigon).

Dr Nguyen Van Dao is the most senior of the seven vice-chairman of the VSRC; in effect he is its director. In an interview made easier with numerous cups of tea, many bananas and sweets he outlined his centre's research programme. The centre is, he says, "the main research institution in Vietnam". It also controls some Government programmes. One of the most important, says Dao, "is an investigation of our natural resources". Dao considers this knowledge to be vitally important for a developing country. The scientists in the centre will be surveying the coastal seabed as well as mapping land resources. Dao adds that many Vietnamese scientists

Alastair Hay was recently in Vietnam as a Nature travelling fellow. He was supported in part by the London Technical Group. 
suspect that the United States could have valuable satellite pictures which would aid the surveys they propose to make. He acknowledges, however, that this information will probably be classified, but maintains that the Vietnamese would make better use of it than the Americans.

The VSRC, says Dao, is really only starting its research programme; its responsibility will increase in the future. Emphasis is currently placed on the problems of agriculture and medicine; on developing the country's electronics industry; and on establishing geophysics and hydrodynamics on a sound basis. "Our aim" says Dao "is to have a modern scientific capability in 15-20 years. This is a great responsibility. We are virtually starting from scratch after 30 years of war and at a time when the country is so short of resources". Dao would welcome extensive collaboration with Western scientists and scientific institutions. This, together with donations of scientific literature and equipment, could help Vietnam meet her twenty year programme. Dao expressed his appreciation for the aid the centre has received from other socialist countries, but adds that there is a desperate need for much more help.

On a tour of the centre it is apparent that some subjects are better provided for than others. Physics is generally acknowledged to be an expensive science, chemistry less so, but costly nevertheless. Historically this is how resources have been apportioned in Vietnam for both physicists and chemists were needed in the war effort. Biology and the other sciences all trailed behind.

The Head of the Institute of Biology, Dr Tuoc, has hopes that this situation is about to change in view of the Government's stated view that agriculture must be accorded more attention. Tuoc emphasises that the VSRC is concerned with basic science, but that this will have a practical application in the future. Some biologists in his Institute are engaged on plant breeding programmes with rice seeds obtained from the International Rice Research Institute in the Philippines; their aim is to produce a crop with a higher nitrogen content and to find a rice variety that will withstand a colder environment. Others are studying diseases of rice and tobacco-two of Vietnam's most important crops. Some of the research in vitamins in progress will include a compilation of these nutrients in the country's foodstuffs. Zoologists are similarly engaged on a programme of cataloguing Vietnam's fauna. The two rooms allocated to them in the Institute of Biology are filled with animal specimens destined eventually

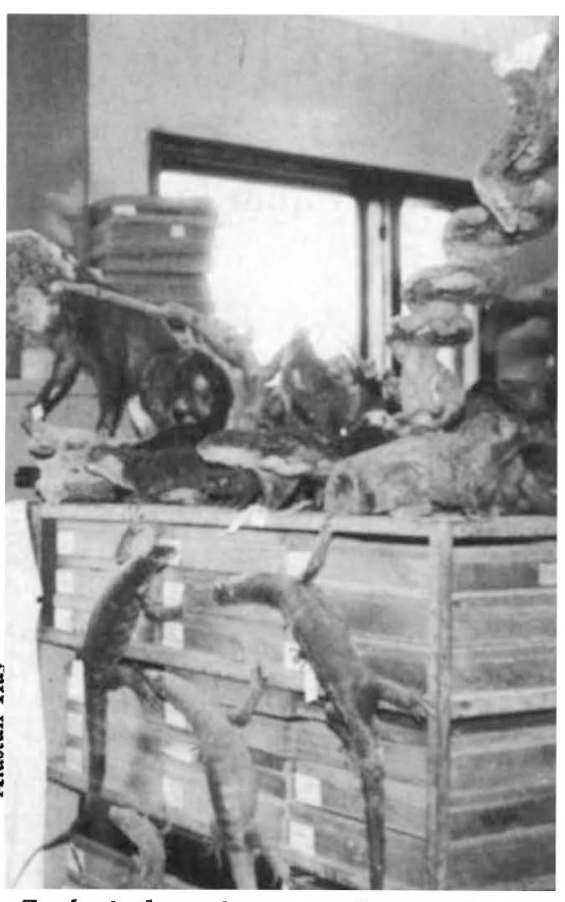

Zoological specimens await attention

for a museum of natural history.

Of the four institutes in the VSRC, physics is by far the best equipped. The physicists have some real successes to their credit, and are perhaps the most confident of Vietnam's scientists. Professor Nguyen Van Hieu is a vicechairman and in charge of the Institute of Physics. Open, warm and very forthcoming, Hieu is a perfect ambassador for Vietnamese science. Hieu is a high energy physicist and a professor at the Dubna high energy physics institute near Moscow. His institute has strong ties with Dubna and some Vietnamese physicists are currently engaged there on 1 to 3 year contracts. Many of the physicists-like most of the other scientists in the centre-are either trained in the Soviet Union or Eastern Europe; some studied in France and Germany.

The real achievement of Hieu's institute is the completion of a fiveyear programme to establish Vietnam's clectronics industry. With many patents and raw matcrials bought from the West the physicists now produce their own transistors. It has proved to be an expensive undertaking, but well worth the financial support provided by the grants from industry. Vietnam's technologists have also worked on the electronics programme for its duration and in preparation for the transition of the work from pilot stage to full scale production. 1978 is destined to be the year of the first Victnamese radio components.

To offset the cost of the transistors the physicists-in co-operation with the earth scientists--are actively studying the properties of Vietnam's natural resources. They hope to find the necessary raw materials to assist with manufacture. In the past most of the research of the institute was of an applied nature; only recently has it been possible to do basic research. The six departments in the physics section cover a variety of topics. In theoretical physics, there are quantum field theorists, and solid-state theorists. In other departments some study semiconductor physics; some optics--for prism and lens manufacture to study the optical properties of semi-conductors and solid state materials-and quantum electronics; some work on technical physics for physical measurement; some on the physics of radiation; and some on crystallography.

The chemistry institute is headed by Dr Khoi Nguyen Huu. Vietnam's chemists are also engaged on a study of the country's natural resources. Their interest is centred on plant terpenes, steroids and alkaloids. In cooperation with botanists, plants used in traditional medicine are being grouped according to their chemical taxonomy. Eventually the active ingredients in the medicaments will be identified and synthesised. Certain stages of the process are feasible at the moment, but for positive fingerprinting all chemicals still have to be sent to forcign laboratories, a process the chemists find very time consuming.

The chemists are also studying the oil resources in Vietnam. The final aim of the programme is to assist industry to extract commercially important oils from anise, citronelle, cinammon, hasilicum, dugenol and mint. With further departments for inorganic analysis in Hanoi, and others for oil chemistry and organic synthesismainly polymer chemistry-in Ho Chi Minh City the chemists have the necessary manpower for their work. Again the real problem is a chronic shortage of equipment and of available chemicals and solvents.

The VSRC is the best equipped of Vietnam's research institutions. Its programme is closely allied to the country's needs. But like all of Vietnam's research institutions it lacks many resources. Scientists, scientific institutions and governments in the West could do a great deal to assist the development of science in Vietnam. The aid which is currently given to Vietnamese scientists by Western doners is still far from adequate. Far more in the form of literature, equipment and exchange facilities for scientific co-operation is required.

When Vietnamese scientists are so obviously keen to make contact with their Western counterparts it surely is an opportunity to be grasped. A generous response from the West would be in order, for Vietnam's burden is one few would wish to carry. 